\title{
Trans 1,2 diaminocyclohexane as a template in the synthesis of ligands for transition metal and actinide in vivo detoxification
}

\author{
Théodorine Bailly, Ramon Burgada, Marc Lecouvey, Alain Neuman, and Thierry Prangé* \\ UMR 7033 CNRS, Laboratoire de Chimie Structurale Biomoléculaire. 74, rue Marcel Cachin, \\ F93017 Bobigny Cedex, France \\ E-mail: prange@lure.u-psud.fr
}

Dedicated to Professor Mrs. Asima Chatterjee on her $85^{\text {th }}$ birthday

(received 01 Dec 03; accepted 16 March 04; published on the web 19 March 04)

\begin{abstract}
Trans 1,2-diamino cyclohexane was used as a template for building EDTA-like derivatives that can act as strong complexation agents in vivo. Cyclohexane diamino tetraphosphonate (CDTP) and diamino diphosphonate (CDDP) ligands were synthetized with the aim to decorporate living organisms for heavy atoms or actinides following accidental ingestion. The stability of the complexes with calcium, copper, and cobalt were obtained in vitro and compared to those of EDTA or DTPA. The X-ray structure of CDDP confirms its strong ability to form highly stable complexes.
\end{abstract}

Keywords: Polyamino phosphonates, actinide complexation, $\mathrm{X}$ ray structure

\section{Introduction}

EDTA (ethylene diamino-tetra-acetic acid), MDTA (methyl ethylene diamino-tetra-acetic acid), DMEDTA (dimethyl ethylene diamino-tetra-acetic acid), or CDTA (trans cyclohexyl 1,2diamino-tetra-acetic acid) are four compounds belonging to the polyamino-carboxylate family. They are known ${ }^{1}$ for their strong chelating properties against a large panel of cations, as given by the $\mathrm{K}_{\mathrm{i}}$ constants listed in Figure 1 .

In the search for specific agents for heavy metal chelation, and especially in the case of in vivo intoxication care, we have developed the synthesis of new poly amino-phosphonic acids 2 with the idea to obtain compounds with increased complexation properties. 
<smiles>O=C(O)CN(CCN(CC(=O)O)CC(=O)O)CC(=O)O</smiles>

$\log K_{i}$

$$
\text { EDTA }
$$

$\mathrm{Ca}(\mathrm{II})$

$\mathrm{Cu}$ (II)

$\mathrm{Fe}$ (III)<smiles>CC(CN(CC(=O)O)CC(=O)O)N(CC(=O)O)CC(=O)O</smiles>

MDTA

11.6

19.8

26.0<smiles>CC(C(C)N(CC(=O)O)CC(=O)O)N(CC(=O)O)CC(=O)O</smiles>

DMEDTA

12.3

21.6

28.2<smiles>O=C(O)CN(CC(=O)O)C1CCCCC1N(CC(=O)O)CC(=O)O</smiles>

CDTA

13.2

21.9

30.0

\section{Figure 1}

Phosphonic derivatives, and the more elaborated hydroxy bis phosphonic acids are widely used as complexing agents for calcium, zinc ${ }^{2,3}$ and/or a number of bivalent metals, they are involved in a large number of biochemical processes and diseases treatments ${ }^{4,5}$ or diagnostics (scintigraphy in the case of ${ }^{99 \mathrm{~m}} \mathrm{Tc}$ ). The aim of this report is to build polyphosphonic compounds grafted to a poly amino tetra-substituted template and to analyze their properties including acidity, stability, kidney clearance, all associated with a mandatory low level toxicity.

\section{Chemistry}

The Kabachnik-Fields reaction was applied to trans 1,2-diamino cyclohexane, 1, according to Figure 2 (left reaction).

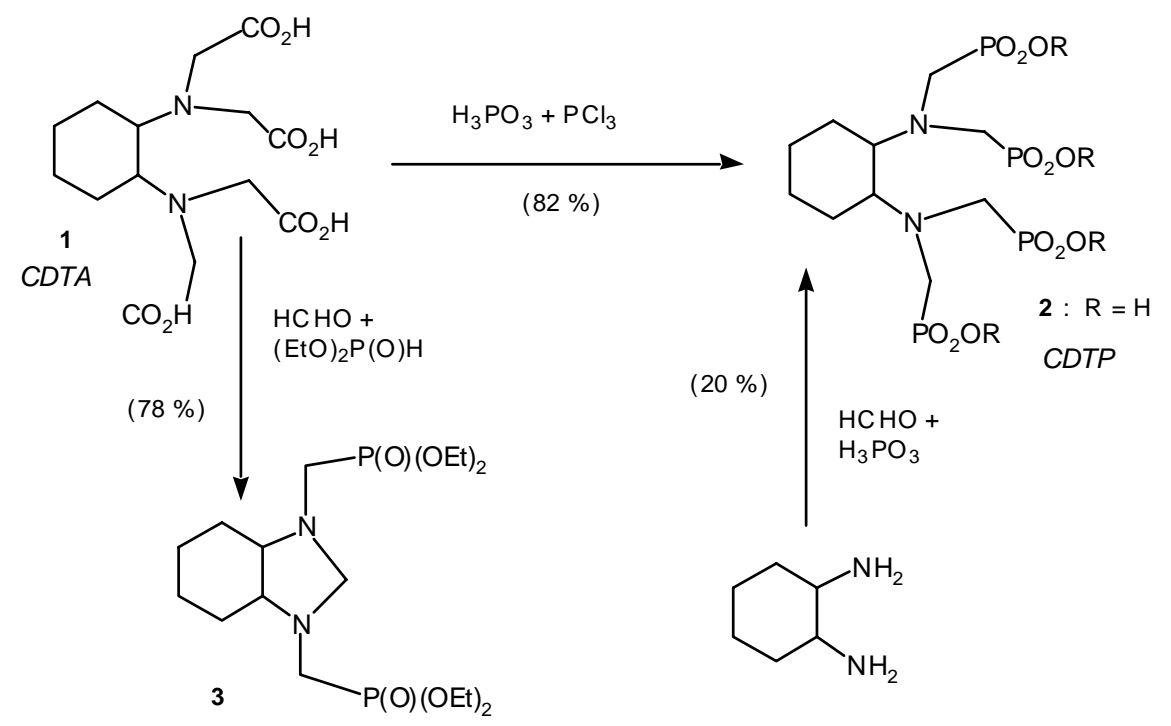

Figure 2 
This led to the bridged bis-phosphonate 3 in $78 \%$ yield. Upon mild hydrolysis $\left(\mathrm{HCl}, 20^{\circ} \mathrm{C}\right)$, the bi-cyclic compound 3 looses its diamino methylene bridge to give the monocyclic di-ester diamino hydrochloride $\mathbf{4 a}$ which in turn, regenerates 3 when its free base $\mathbf{4}$ is treated with tetramethyl di-amino-methane ${ }^{6}$ (Figure 3). Notice however that the methylene bridge in 3 remains stable in basic medium. Thus the bicyclic diacid $\mathbf{3}^{\prime}$ may be obtained using bromo trimethyl silane in methanol while the unbridged diacid 4' results from either strong acid $(\mathrm{HCl}$ $35 \%)$ or mild $\left(\mathrm{H}_{\mathrm{Cl}} 0.1 \mathrm{M}\right)$ hydrolysis from $\mathbf{4 a}$ or $\mathbf{3}^{\prime}$, respectively.

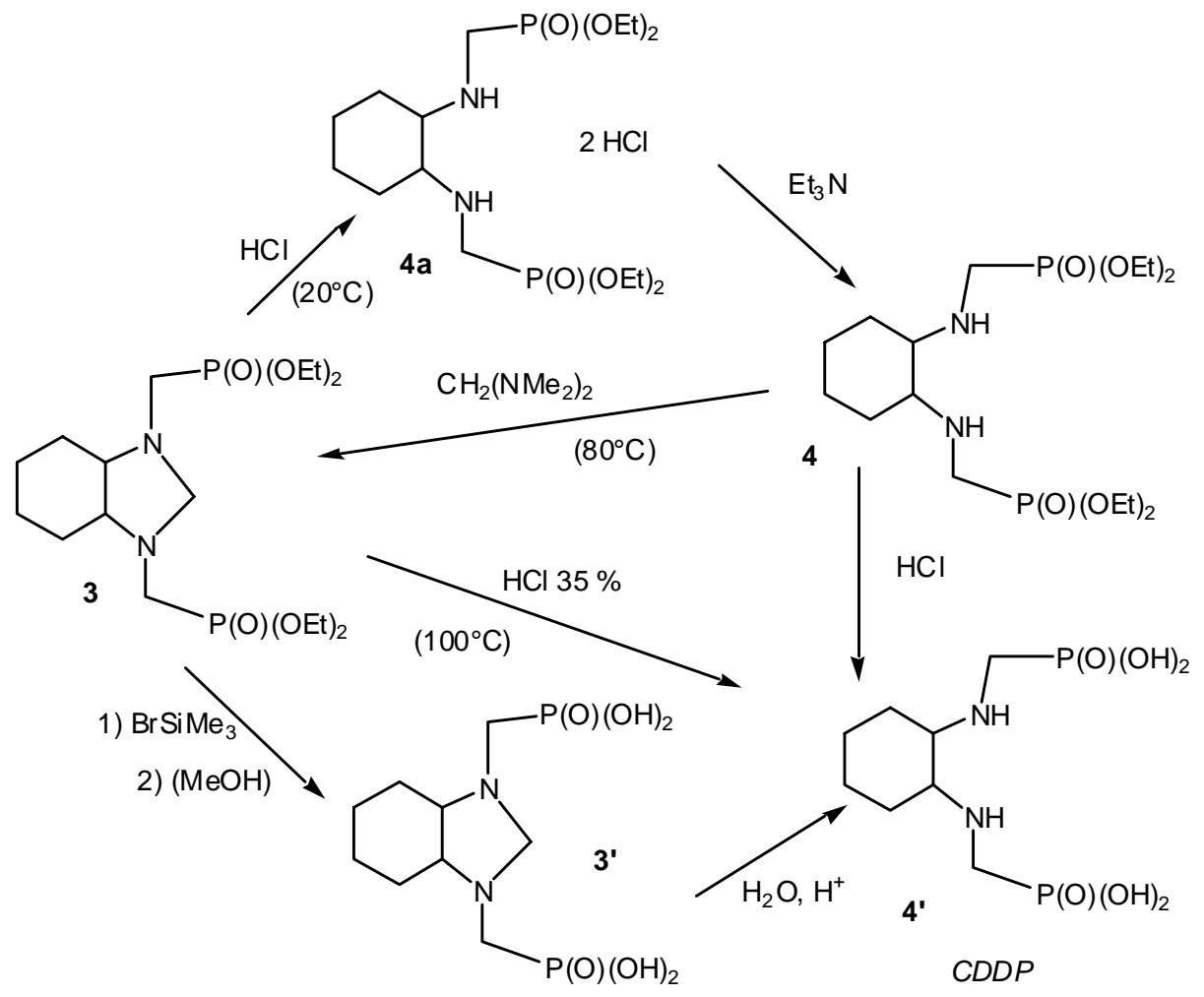

\section{Figure 3}

The synthesis of the tetra-acid 2 or CDTP (Figure 2) was first attempted from the more available trans diamino cyclohexane (Moedritzer-Irani reaction). This resulted in a mixture including six other side-products relatively difficult to separate. The yield of CDTP (20\%) was estimated only from analytical methods.

Finally, the best way to obtain CDTP 2 was to apply the method described by Kruger and Bauer ${ }^{7}$ to 1 as shown in Figure 2 . In that case, $82 \%$ yield is obtained routinely.

\section{X-ray structure of CDTP 4'}

To ascertain the structure of the di-amino di-phosphonic acid $\mathbf{4}^{\prime}$ and to determine the hydrogen bond net in the molecule, an X-ray diffraction analysis was performed. Compound $\mathbf{4}^{\prime}$ is very soluble in water and a monocrystal was prepared by slow evaporation of a concentrated 
water/methanol solution at room temperature. This resulted in a hard crystalline mass from which it was possible to break out a single colorless micro-crystal $(0.1 \times 0.05 \times 0.02 \mathrm{~mm})$. Diffraction data were collected on a synchrotron beam line with the temperature set at $100 \mathrm{~K}$ using a cryo-cooled nitrogen gas stream.

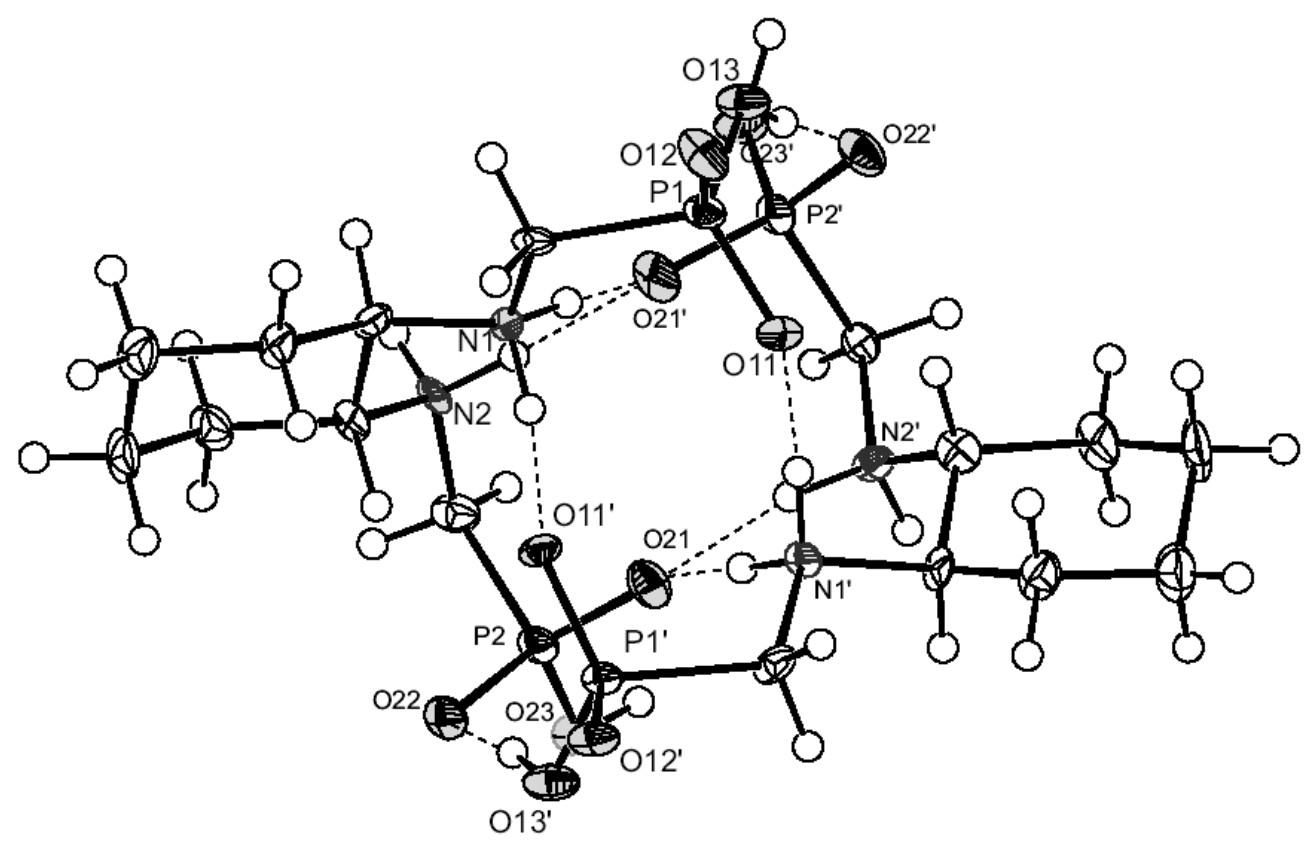

Figure 4. ORTEP view of the head-to-tail association in CDTP. Hydrogens are drawn as circles of arbitrary radii.

At such a temperature, all hydrogen atoms were located and refined using isotropic individual factors. Details about the structure determination are given in the experimental section.

\section{Results and Discussion}

The asymmetric unit contains two molecules of 4', one water, and one methanol solvate molecules. The structure consists of a strong head-to-tail association of two bis-zwitterionic CDDP (each bearing two $\mathrm{NH}_{2}^{+}$groups and two $\mathrm{PO}_{3} \mathrm{H}^{-}$phosphonates), around a local, two-fold axis, through eight hydrogen bond interactions between their phosphonate/amino moieties. The dimer itself associates in the three directions via polar interactions involving seven more hydrogen bonds directed toward the protonated nitrogens, the oxygens of the phosphonates, and the solvated water/methanol molecules present in the packing. The shortest distances are reported in Table 1. It is remarkable that all the polar atoms $\left(\mathrm{NH}_{2}{ }^{+}\right.$and phosphonate oxygens) participate to hydrogen bonds either within the dimer (the four amino hydrogens, O11, O13, $\mathrm{O} 21, \mathrm{O} 22$, in each mate) or inter-dimer (O12, O23 for each, plus the solvated molecules). Figure 
4 represents the ORTEP view (drawn by the $P L A T O N{ }^{8}$ program) of the CDTP dimer, with ellipsoids at the $50 \%$ probability level.

Table 1. Intermolecular polar interactions in the crystal structure of CDDP 4' (in $\AA$, standard deviations in parentheses). Prime labels refer to the second molecule of the dimer. Labels of hetero-atoms are reported in Figure 4; $\mathrm{O}(1)_{\mathrm{W}}$ and $\mathrm{O}(2)_{\mathrm{W}}$ are the oxygens of the solvated methanol and water molecules (not shown in Figure 4)

\begin{tabular}{|c|c|c|c|c|c|}
\hline Atoms & \multicolumn{3}{|c|}{ Distances $(\AA)$} & \multirow[t]{2}{*}{ sym. op.* } & \multirow{2}{*}{$\frac{\text { Angles }\left({ }^{\circ}\right)}{\text { D--H....A }}$} \\
\hline Donnor--H.....Acceptor & D--H & $\mathrm{H} \ldots \mathrm{A}$ & $\mathrm{D} \ldots \mathrm{A}$ & & \\
\hline $\mathrm{N}(1)--\mathrm{H}_{1} \ldots . . \mathrm{O}\left(11^{\prime}\right)$ & $0.94(3)$ & $1.71(3)$ & $2.627(5)$ & - & $163(4)$ \\
\hline $\mathrm{O}(1)_{\mathrm{W}}-\mathrm{H} \ldots . . \quad \mathrm{O}(22)$ & $0.97(5)$ & $1.81(6)$ & $2.751(5)$ & {$[3565]$} & $163(5)$ \\
\hline $\mathrm{N}(1)--\mathrm{H}_{2} \ldots . \quad \mathrm{O}\left(21^{\prime}\right)$ & $0.95(4)$ & $1.74(4)$ & $2.683(5)$ & - & $172(5)$ \\
\hline $\mathrm{N}(2)--\quad \mathrm{H}_{1} \ldots . . \mathrm{O}\left(12^{\prime}\right)$ & $0.95(5)$ & $1.79(5)$ & $2.721(5)$ & [4564] & $168(5)$ \\
\hline $\mathrm{N}(2)--\quad \mathrm{H}_{2} \ldots . . \mathrm{O}\left(21^{\prime}\right)$ & $0.94(3)$ & $1.76(3)$ & $2.694(6)$ & - & $175(2)$ \\
\hline $\mathrm{N}\left(1^{\prime}\right)--\mathrm{H}_{1} \ldots . \quad \mathrm{O}(21)$ & $0.94(3)$ & $1.75(3)$ & $2.693(6)$ & - & $172(4)$ \\
\hline $\mathrm{N}\left(1^{\prime}\right)--\mathrm{H}_{2} \ldots . \quad \mathrm{O}(11)$ & $0.95(3)$ & $1.73(3)$ & $2.683(5)$ & - & $176(4)$ \\
\hline $\mathrm{N}\left(2^{\prime}\right)--\mathrm{H}_{1} \ldots . \quad \mathrm{O}(2)_{\mathrm{W}}$ & $0.96(4)$ & $1.77(3)$ & $2.731(5)$ & {$[3565]$} & $174(4)$ \\
\hline $\mathrm{N}\left(2^{\prime}\right)--\mathrm{H}_{1} \ldots . \quad \mathrm{O}(21)$ & $0.95(3)$ & $1.77(3)$ & $2.701(6)$ & - & $165(5)$ \\
\hline $\mathrm{O}(13)--\mathrm{H} \ldots . . \quad \mathrm{O}\left(22^{\prime}\right)$ & $0.90(5)$ & $1.65(6)$ & $2.551(5)$ & - & $177(3)$ \\
\hline $\mathrm{O}\left(13^{\prime}\right)--\mathrm{H} \ldots . . \quad \mathrm{O}(22)$ & $0.88(3)$ & $1.79(3)$ & $2.661(4)$ & - & $170(5)$ \\
\hline $\mathrm{O}\left(23^{\prime}\right)--\mathrm{H} \ldots . . \quad \mathrm{O}(1)_{\mathrm{W}}$ & $0.89(4)$ & $1.70(4)$ & $2.581(5)$ & {$[4564$} & $168(6)$ \\
\hline $\mathrm{O}(2)_{\mathrm{W}}--\mathrm{H} \ldots . . \quad \mathrm{O}(12)$ & $0.90(4)$ & $1.82(5)$ & $2.682(5)$ & {$[2545]$} & $161(5)$ \\
\hline $\mathrm{O}(2)_{\mathrm{W}}--\mathrm{H} \ldots . . \quad \mathrm{O}\left(12^{\prime}\right)$ & $0.89(5)$ & $1.86(5)$ & $2.739(5)$ & - & $170(6)$ \\
\hline $\mathrm{O}(23)--\mathrm{H} \ldots . . \quad \mathrm{O}(12)$ & $0.89(4)$ & $1.66(4)$ & $2.552(5)$ & [4564] & $176(4)$ \\
\hline
\end{tabular}

In Figure 1 are reported the complexation constants $\mathrm{K}_{\mathrm{i}}$ for a panel of representative molecules related to EDTA ${ }^{1,9,10}$. Although the corresponding phosphonate homologues have already been synthesized ${ }^{11,12}$, the corresponding $\mathrm{K}_{\mathrm{i}}$ were not fully investigated. CDDP or compound 4', presents all the required characteristics for a strong affinity toward cations. This molecule has been involved in the transport of ${ }^{153} \mathrm{Sm}$ as a therapeutic vector when linked to a specific antibody ${ }^{11}$. In the crystal structure of CDDP, evidence of a complicated 3D network is observed that clearly shows the ability of $4^{\prime}$ to build strong polar interactions.

The use of CDDP and CDTP (compound 2), in the fixation of cobalt(II) is under investigation. Preliminary results show the immediate formation of a specific complex when one eqv. sodium colbatinitrite is added to the sodium salt of CDTP. The complex is very soluble and staable in water. Its ${ }^{31} \mathrm{P}$ NMR spectrum in $\mathrm{D}_{2} \mathrm{O}$ shows a upfield shift of $23 \mathrm{ppm}$ compared to the uncomplexed form. All other spectroscopic measurements are in favor of the formation of the stable 1:1 complex depicted in Figure 5. 


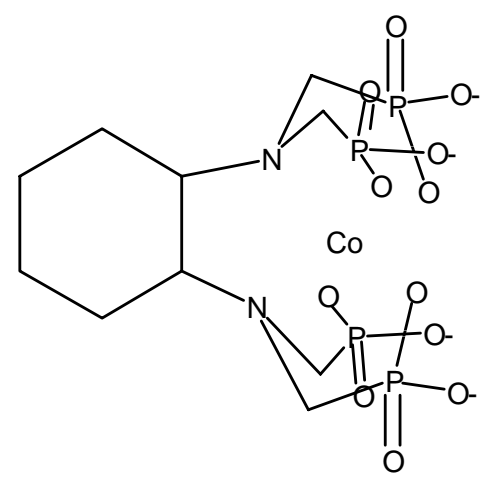

Figure 5

Table 2. ${ }^{31} \mathrm{P}$ and ${ }^{1} \mathrm{H}$ NMR data of 2-4': $\delta[\mathrm{ppm}]$ and coupling constants $J[\mathrm{~Hz}]$

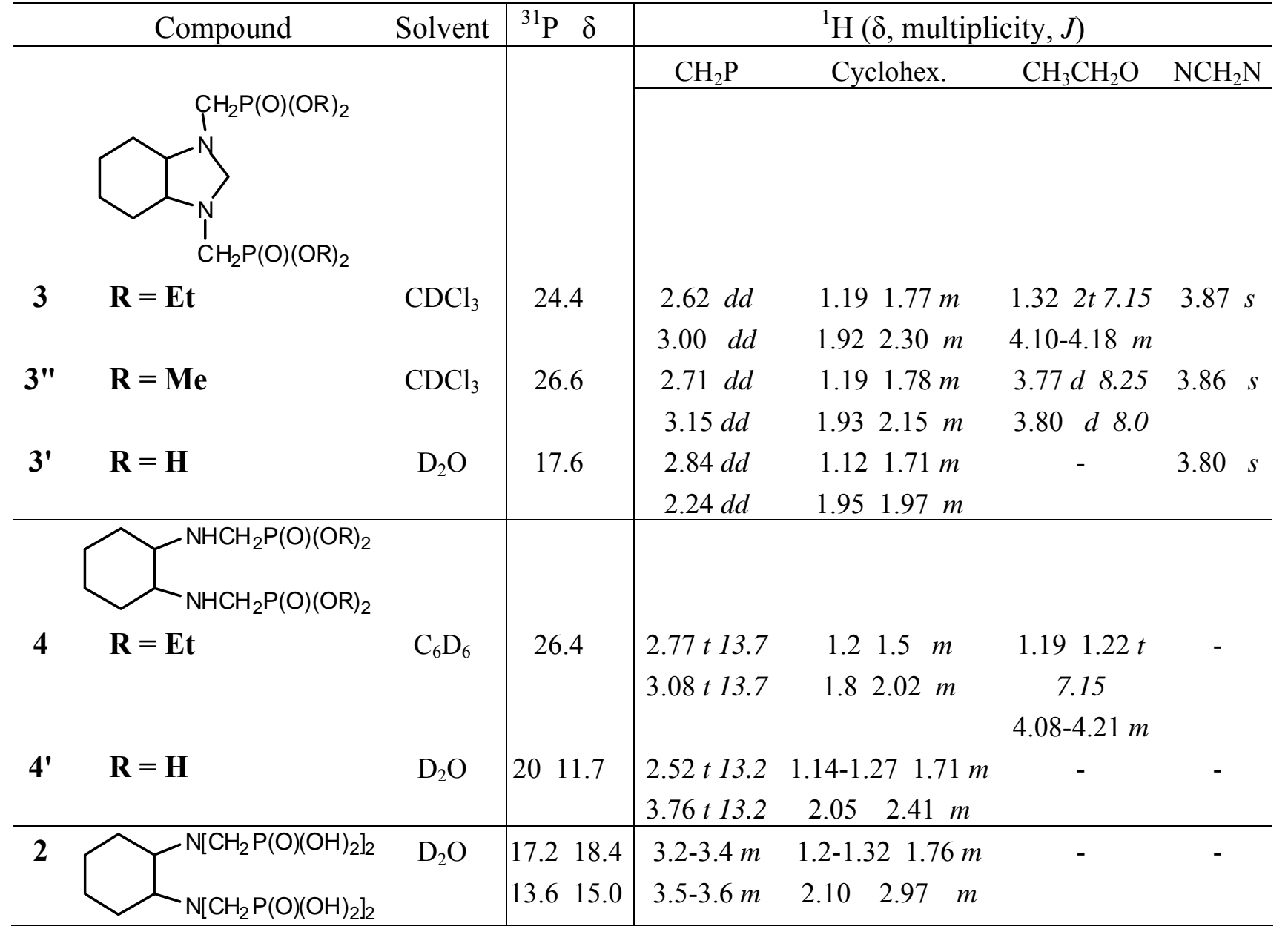

The bridged diacid $\mathbf{3}^{\prime}$ is remarkably soluble in water but relatively unstable at neutral $\mathrm{pH}$ due to the loss of the methylene bridge. However it is possible to characterize it by NMR as its di- 
sodium salt (in $\mathrm{D}_{2} \mathrm{O} / \mathrm{NaOD}$ ) - Table 2 - and to follow the degradation over a period of several days by monitoring the disappearance of the methylene signal.

\section{Conclusions}

Two diamino tetraphosphonic (CDTP, 2) and diamino diphosphonic (CDDP, 4') compounds were synthesized, in high yield. The crystal structure of CDDP was determined by X-ray diffraction as an unusual very tight dimer maintained by eight hydrogen bonds. CDDP and CDTP represent two of the most promizing agents for complexing bivalent cationic species, as observed with transition metals. These properties are under investigation and a number of derivatives are currently under development for selective actinide recognition.

\section{Experimental Section}

General Procedures. $\mathrm{CCl}_{4}\left(99.95 \%\right.$, analytical reagent, PROLABO), $\mathrm{CHCl}_{3}$ (HPLC grade, PROLABO), MeOH (HPLC grade, PROLABO) were distilled before use and were dried by means of $4 \AA$ molecular sieves. THF was obtained by distillation from the sodium ketyl of benzophenone. Triethylamine was distilled over KOH and was stored over $4 \AA$ molecular sieves. Melting points were determined with a Koffler apparatus.

X-ray diffraction experiments on CDDP (compound 4'), were performed at the LURE synchrotron facility in Orsay, on the W32 beam line ${ }^{13}$. The wavelength was set to $0.948 \AA$ and data recorded on a MAR Research MAR345 Image Plate detector. The crystal was first dipped in nujol oil then mounted with a cryoloop, in the stream of nitrogen gas at a temperature of $100 \mathrm{~K}$. The crystal to detector distance was set as to get the highest resolution possible $(0.95 \AA$ at the edge, according to the geometry of the beam line and wavelength). Data consist of 100 frames, three degree-rotation each, they were processed with the DENZO ${ }^{14}$ program. The structure was solved using SHELXS ${ }^{15}$ and refined with SHELXL ${ }^{16}$ program. All non hydrogen atoms were refined with anisotropic thermal parameters, while hydrogens were refined using isotropic thermal parameters. Crystal data: Monoclinic, space group P21/c, $a=11.347(2), b=16.621(2)$, $c=16.140(2) \AA, \beta=100.73(7)^{\circ}$. The final $R$ factor is 0.048 for observed reflections (2652 with $F \geq 2 \sigma(F)), R=0.052$ for all the reflections (2937), $R w=0.142$ for all $F^{2}$. Coordinates and structure factors are available from the authors (T.P.). They have been deposited with the Crystallographic Data Centre, 40, Union road, CB2 1EZ Cambridge, UK (deposition number CCDC 225410).

NMR spectra: All NMR experiments were done using a VARIAN UNITY INOVA spectrometer $(11,7 \mathrm{~T})$ operating at a proton frequency of $500 \mathrm{MHz}$. Temperatures were calibrated with an ethylene glycol test tube. Proton spectra were calibrated using external trimethylsilyl-3-propionic acid- $\mathrm{d}_{4}$ 2,2,3,3-sodium salt (TMSP) as reference. ${ }^{13} \mathrm{C}$ chemical shifts 
were calibrated using external iodomethane reference at $-22 \mathrm{ppm}$. The ${ }^{31} \mathrm{P}$ NMR spectra were recorded using phosphoric acid as external reference.

[3-(Diethoxy-phosphorylmethyl)-octohydro-benzoimidazol-1-ylmethyl]- phosphonic acid diethyl ester 3. To a magnetically stirred solution of trans 1,2-diaminocyclohexane (3.42 g, 30 $\mathrm{mmol})$ in anhydrous THF $(40 \mathrm{~mL})$, diethyl phosphite $(8.3 \mathrm{~g}, 60 \mathrm{mmol})$ was slowly added. The reaction mixture was refluxed before the addition of paraformaldehyde $(2,8 \mathrm{~g}, 93 \mathrm{mmol})$. After heating under reflux for $4 \mathrm{~h}$, the solvent was evaporated under reduce pressure. The residue was dissolved in $\mathrm{CHCl}_{3}(50 \mathrm{ml})$ and the organic layer was washed twice with $\mathrm{H}_{2} \mathrm{O}(2 \mathrm{x} 10 \mathrm{ml})$ and dried over $\mathrm{Na}_{2} \mathrm{SO}_{4}$. The chloroform was evaporated under vacuum. A crude yellow oil (10 g) was obtained. This oil was purified by Kugelrohr distillation $\left(\mathrm{T}=280{ }^{\circ} \mathrm{C}, 0,1 \mathrm{~mm} \mathrm{Hg}\right)$ in $78 \%$ yield.

Anal. Calcd. for $\mathrm{C}_{17} \mathrm{H}_{36} \mathrm{~N}_{2} \mathrm{O}_{6} \mathrm{P}_{2}$ (426.43): C 47.88; H 8,45; N 6.57; P 14,55. Found C 47,44; $\mathrm{H}$ 8.62 ; N 5,85; P 14.10 .

[3-(Dimethoxy-phosphorylmethyl)-octohydro-benzoimidazol-1-ylmethyl]-phosphonic acid di-methyl ester 3". The compound 3" was prepared and purified following the same procedure with dimethyl phosphite. The reaction was completed after 1 hour under reflux in $60 \%$ yield.

(3-Phosphonomethyl-octohydro-benzoimidazol-1-ylmethyl)-phosphonic acid 3'. To a magnetically stirred solution of the compound 3 (2 g, 4,69 mmol) in carbon tetrachloride (40 $\mathrm{mL})$, trimethylsilyl bromide $(5.75 \mathrm{~g}, 37.5 \mathrm{mmol})$ was slowly added. The reaction mixture was stirred during $70 \mathrm{~h}$. at room temperature. The solvent was evaporated under reduce pressure. The residue was dissolved in methanol $(50 \mathrm{ml})$ and the product precipitated from $\mathrm{MeOH}$ after 30

min. of stirring. After filtration, the powder was dried under vacuum to give 3' (0.8 g) in $54 \%$ yield. $\mathrm{Mp}=205^{\circ} \mathrm{C}$.

(\{2-[(Diethoxy-phosphorylmethyl)-amino]-cyclohexylamino\}-methyl)-phosphonic acid diethyl ester 4 (from compound 3). To a magnetically stirred solution of compound 3 (2,5 g, 5,86 $\mathrm{mmol})$ in methanol $(15 \mathrm{~mL}), 3 \mathrm{ml}$ of concentrated hydrochloric acid was slowly added. The reaction mixture was stirred during $4 \mathrm{~h}$ at room temperature. The reaction was monitored by ${ }^{31} \mathrm{P}$ NMR. If the hydrolysis was not complete, the solution was heated at $40-50{ }^{\circ} \mathrm{C}$ during $10 \mathrm{~min}$. The solvent was evaporated under reduce pressure, diluted by water $(15 \mathrm{ml})$ and concentrated again. This procedure was carried out twice and water and excess of hydrogen chloride were entirely eliminated by co-evaporation. Water $(5 \mathrm{ml})$ was then added and the $\mathrm{pH}$ of the solution was raised to 9 by addition of a sodium hydroxide solution $(1 \mathrm{M})$. The aqueous solution was extracted three times by ether $(20 \mathrm{~mL})$. The organic layers were dried with $\mathrm{MgSO}_{4}$ and evaporated to dryness. A yellowish oil was obtained in $45 \%$ yield.

Synthesis of [3-(Diethoxy-phosphorylmethyl)-octohydro-benzoimidazol-1-ylmethyl]- phosphonic acid diethyl ester 3 (from compound 4). Compound 4 ( $0.3 \mathrm{~g}, 0.704 \mathrm{mmol}$ ) was placed in a three-necked flask equipped with a magnetic stirrer, an addition funnel, a thermometer and a nitrogen inlet tube. Bis(dimethylamino) methane $(0,8 \mathrm{~g}, 7,8 \mathrm{mmol})$ was then added. The mixture was stirred and heated at $80^{\circ} \mathrm{C}$. The dimethylamine was removed by the nitrogen flow and 
neutralized by a solution of hydrochloric acid $(0,1 \mathrm{M})$. After $30 \mathrm{~min}$., the reaction was complete. The excess of aminal was removed under vacuum $\left(0,1 \mathrm{~mm} \mathrm{Hg}-50^{\circ} \mathrm{C}\right.$.). 3 (oil) was obtained in quantitative yield.

\{[2-(Phosphonomethyl-amino)-cyclohexylamino]methyl\}-phosphonic acid $4^{\prime}$ (CDDP). Method 1: To a magnetically stirred solution of the compound 3, $15 \mathrm{ml}$ of concentrated hydrochloric acid were added. The reaction mixture was refluxed during $20 \mathrm{~h}$. The solvent was evaporated under reduce pressure and the residue was lyophilised. The reaction was quantitative. Method 2: To a magnetically stirred solution of the compound 4, $15 \mathrm{ml}$ of dilute hydrochloric acid were added. The reaction mixture was stirred at room temperature during $4 \mathrm{~h}$. The solvent was evaporated under reduce pressure and the residue was lyophilised. The reaction was quantitative.

(\{[2-(Bis-phosphonomethyl-amino)-cyclohexyl] phosphonomethyl-amino\}-methyl)-phosphonic acid 2.

Method 1. Moedritzer-lrani procedure. Trans 1,2-diamino cyclohexane (114g, $1 \mathrm{~mol})$ in concentrated hydrochloric acid $(200 \mathrm{ml})$ was placed in a three-necked flask equipped with a magnetic stirrer, an addition funnel, a thermometer and a nitrogen inlet tube. Dry phosphorous acid (328 g, $4 \mathrm{~mol}$ ) was then added. The mixture was refluxed. Formol $(10 \mathrm{~mol})$ was then added dropwise and the mixture refluxed for $8 \mathrm{~h}$. The solvent was evaporated under reduce pressure and a brown residue was obtained. An aqueous solution of ethanol (10\% water) was added on the residue and the mixture was refluxed. The solution was filtrated and the precipitate was extracted with hot acetone. After evaporation of the solvent, compound $\mathbf{2}$ was obtained in $20 \%$ yield.

Method 2. 1.2-diamino cyclohexane N,N.N'.N' tetra acetic acid (3.46 g, $9.05 \mathrm{mmol})$ in suspension of chlorotoluene $(20 \mathrm{ml})$ was placed in a three-necked flask equipped with a magnetic stirrer, an addition funnel, a thermometer and a nitrogen inlet tube. Dry phosphorous acid (3,28

$\mathrm{g}, 40 \mathrm{mmol})$ was then added. The mixture was heated at $80{ }^{\circ} \mathrm{C} . \mathrm{PCl}_{3}(5.5 \mathrm{~g}, 40 \mathrm{mmol})$ was then slowly added and the temperature was maintained during $2 \mathrm{~h}$. The organic solvent was removed by decantation and the yellow residue was diluted by water (slightly exothermic). After filtration, the aqueous solution was concentrated under vacuum. On addition of a large excess of methanol, a white precipitate was then observed. After filtration, a white powder was obtained in $83 \%$ yield.

$\mathrm{Mp}=300^{\circ} \mathrm{C}$. Anal. Calcd. for $\mathrm{C}_{10} \mathrm{H}_{26} \mathrm{~N}_{2} \mathrm{O}_{12} \mathrm{P}_{4}$ (490): C 24.48; H 5,3; N 5.71; P 25.3. found C 24.01; H 5.9; N 4.99; P 24.3

\section{References}

1. Shkol'nikova, L. M.; Porai-Koshits, M. A. Russian Chem. Rev. 1990, 59, 643.

2. Dufau, C.; Benramdane, M.; Leroux, Y.; El Manouni, D.; Neuman, A.; Prangé, T.; Sylvestre J. P.; Gillier, H. Phosphorus, Sulfur Silicon Relat. Elem. 1995, 107, 145.

3. Silvestre, J.P.; Quy Dao, N.; Leroux, Y. Heteroatom. Chem. 2001, 12, 73. 
4. Fleisch, H. Prog. Mol. Subcell Biol. 1999, 23, 197.

5. Brown, J. E.; Coleman, R. E. Breast Cancer Res. 2002, 4, 24.

6. Bailly, T.; Burgada, R. Phosphorus, Sulfur Silicon Relat. Elem. 1995, 101, 131.

7. Kruger, F.; Bauer, L. Chem-Ztg. 1972, 36, 691.

8. PLATON - Version of January 2002. Speck, A. L.; University of Utrecht, The Netherlands 2002.

9. Hancock, R. D; Martell, F. Chem. Rev. 1989, 89, 1875.

10. De Souza, A. S.; Croft, G. J. B.; Wagner, C. A.; Mickail, J. P.; Hancock, R. D. Inorg. Chem. J. Chem. Soc., Perkin Trans. 1 1991, 30, 3525.

11. Loussouarn, A.; Duflos, M.; Benoist, E.; Chatal, J. F.; Le Baut, G.; Gestin, J. F. J. Chem. Soc., Perkin Trans. 1 1998, 2, 237.

12. Loussouarn, A.; Ouadi, A; Morandeau, L.; Remaud, P.; Giles, R.; Gestin, J. F.; Webb, J. Tetrahedron Lett. 2003, 44, 3539.

13. Fourme, R.; Dhez, P.; Benoit, J. P.; Kahn, R.; Dubuisson, J. M.; Besson, P.; Frouin, J. Rev. Sci. Instrum. 1992, 63, 982.

14. Otwinowsky, Z.; Minor, W. Meth. Enzymol. 1997, 276, 307.

15. SHELXS86 - A program for crystal structure solution. Sheldrick, G. M.; Institut für Anorganische Chemie der Universität, Tammanstrasse 4, D-3400 Göttingen, Germany 1986.

16. Schneider, T. R.; Sheldrick, G. M. Acta Crystallogr. Sect. D 2002, 58, 1772. 